\title{
Developing An Engineering Identity In Early Childhood
}

\author{
Michelle L. Pantoya, Ph.D., Texas Tech University, USA \\ Zenaida Aguirre-Munoz, Ph.D., Texas Tech University, USA \\ Emily M. Hunt, Ph.D., West Texas A\&M University, USA
}

\begin{abstract}
This project describes a strategy to introduce young children to engineering in a way that develops their engineering identity. The targeted age group is 3-7 year old students because they rarely experience purposeful engineering instruction. The curriculum was designed around an engineering storybook and included interactive academic discussions as well as a creative drawing activity. Results provide evidence that students developed an engineering identity based on their illustrations of themselves working as engineers. These findings lend support to the use of engineering-centered books to improve the impact of instructional strategies that emphasize the engineering design cycle. We show how both the curricular materials and the activities can work together to develop an engineering identity in this age group.
\end{abstract}

Keywords: Literacy; Kindergarten; Engineering Education Engineering; STEM, STEM Education; Creativity; Identity; Children's Books

\section{INTRODUCTION}

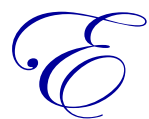

ngineers design technologies using an understanding of science and math. In this way engineering provides the glue to hold science and math together and provides meaningful situational context. When we asked over 300 3-7 year olds "What do engineers do?" the number one answer was: I don't know. The $2^{\text {nd }}$ most popular answer was: They drive a train. These responses reflect the nationwide fundamental lack of understanding of engineering. Yet, early Science, Technology, Engineering and Mathematics (STEM) education has become a major focus of the National Academies stimulated largely because research has shown that by 4 th grade, students who have limited exposure to early STEM education are lacking key mathematics and science skills and background knowledge (STEM Smartbrief, 2011; National Academies Press 2011, 2014). By $4^{\text {th }}$ grade there is a decline in STEM interest and this decline has been linked to: (a) a lack of consistent focus in science content and literacy in the early grades (Cunningham et al., in press); (b) a lack of instructional methods that build on young children's curiosity to explore the world around them (Kang et al., 2010); and, (c) a lack of focus on science content literacy (Gibbons, 2002).

Introducing and engendering excitement about engineering in the early grades $\left(\mathrm{K}-2^{\text {nd }}\right)$ with innovative teaching techniques is a challenge when less than $10 \%$ of instructional time is spent teaching science and teaching engineering is significantly less (Romance and Vitale, 1992; Mantzicopoulos et al., 2008 and 2009). This challenge can be addressed by linking engineering with literacy instruction: the primary instructional focus for this age group. Moreover, since engineering uses math and science to solve problems, a focus on engineering content will elicit young children's situational understanding of science and math.

We argue these early experiences are critical to developing a students' engineering identity; a concept we have drawn from research in academic identity development. Academic identity is a multifaceted concept that refers to one's self-understanding related to academic values, school belonging, regard, and performance (Osborne, \& Jones, 2011). Academic identity is important because of the known relationship between a student's academic identity and the types of goals a student will adopt which, in turn, affect the types of strategies and behaviors the student adopts in an academic setting (Was, Al-Harthy, Oden, \& Isaacson, 2009). Past research indicates that mathematics and science identity contribute in significant ways to a student's ability to persist in challenging math 
and science courses as well as major in and complete mathematics or science post-secondary degrees. Past research also documents the importance of the K-12 learning context in developing students' academic identities (e.g., Berry, Thunder, \& McClain, 2011). Therefore, if the learning context reinforces accurate conceptions of engineering and engaging design activities, it can support the development of positive engineering identity.

Our efforts to help teachers infuse engineering into literacy instruction were challenging due to the lack of engineering-centered books appropriate for early childhood. Also missing are evidence-based approaches to integrating engineering and literacy in ways that enable students to make meaning of science, engineering and text that lead to content rich instruction and impactful improvement in the overall achievement of elementary students as well as cultivate a passion for STEM.

Science texts pose a challenge to elementary students because of a lack of familiarity with scientific vocabulary and concepts (Fang et al., 2010; Bintz et al., 2010; Donohoo, 2010). These problems could be addressed through exposure to purposefully engineered STEM literature in the earlier grades that builds familiarity with science vocabulary, understanding of complex concepts, and establishes connections through real-world, meaningful engineering applications.

To address this void in the literature, our objectives were to develop an engineering-centered literacy book and test instructional practices that would lead to increasing young children's understanding of engineering while exercising their creativity and interest in an engineering profession. The objectives were accomplished using a storybook to introduce technology and engineering coupled with academic discussions to solidify fundamental concepts and a drawing activity to introduce the engineering design process and develop the student's engineering identity.

\section{The Project: Book Reading and Drawing Activity}

Our strategy is to promote STEM learning in Pre-K $-2^{\text {nd }}$ grade using engineering-centered literacy practices that can complement or be integrated into national science curricula developed by FOSS, GEMS, Insights, and STC (aligned with strategies in NRC 2007, 2008 \& 2012) as well as standard literacy programs. The quality of the story books is vitally important as they serve multiple functions. First, they must incite STEM enthusiasm through a situational engineering context and serve as an initial hook into the content literacy lesson. Second, the book needs to introduce fundamental STEM concepts that often go unexplored in the early STEM curricula. Third, the book must serve to scaffold initial discussions of complex STEM concepts that can be developed with student discussions and careful questioning. Fourth, the book must provide a foundational catalyst for related learning tools and curriculum.

The book presented here is Engineering Elephants (Hunt and Pantoya, 2010) and reflects these key features. The authors introduced this lesson in many classrooms ranging from pre-K to $2^{\text {nd }}$ grade with classroom sizes ranging from 10 to 20 students. The lesson described here has been refined over 3 years and about 50 different classroom implementations. The book's narrative structure can be used as an initial scaffold to STEM content, vocabulary, and communication patterns. In this way, it can be used to develop students' background knowledge before engage in more complex engineering discussions and activities. Building background is paramount when working with young and underserved students.

The lesson begins with a teacher or facilitator asking students the question: "What do engineers do?" Childrens' responses are written on a board for all students to see. This discussion can continue for several minutes with additional probes asking if the students know any engineers and what kinds of things those people do. This introductory conversation provides the teacher or facilitator with information about the student's prior knowledge and conceptions about engineering as well as serve as a smooth transition for the introduction of the book, Engineering Elephants.

The story teaches that engineers solve our everyday problems by designing technologies that range from rockets to prosthetics and by engaging them through an interactive journey of an elephant and his questioning of the world around him. The text was composed using the language of science (i.e., asking questions) and uses vibrant 
water color artwork to provide context clues and deeper understanding. This text structure is important to show how an understanding of science leads to the development of technologies, such that engineers use science.

Setting up the context for the book read-aloud, students are told that the story describes what engineers do, and they can help answer questions in the book. Easy to answer questions are purposefully placed throughout the story to simultaneously instill student confidence while maintaining their interest. For this age group, this approach is effective at keeping their attention. Example questions are 'do engineers make elephants?' Children resoundingly respond ' $n o$ ' which initiates their thinking about the things that engineers could design versus those they could not design, and distinguish between natural resources and human made technologies.

Each question is followed by introducing students to content vocabulary through a lyrical, rhyming structure purposefully composed to entice children to anticipate what comes next. Stanzas such as the following in reference to race cars purposefully teach words like force and also reinforce that engineers design things.

There are forces that slow down these cars

The worst of these is drag

Race cars designed by engineers

Are the first at the checkered flag

Engineering Elephants was designed to be used as a provocation for other curriculum and is not plot driven, such that at any point, the iteration between asking questions followed by lyrical presentation of STEM concepts can be interrupted. The final page concludes the elephant's journey at a drafting table thinking about all the technologies that engineers create and asking "When you grow up to be an engineer, what new things will you create?"

At this point, children's responses to the initial question are reviewed and prompted for more responses about what engineers do. New responses are added and some are subtracted from the list so that the group can collectively gain an understanding of engineering through their own student talk. Moore et al. (2012) identified the student's ability to take in thoughts and ideas from others as well as convey their own thoughts and ideas in a coherent manner as an important component of the engineering framework. . Towards this end, these academic discussions are an important part of the activity.

The academic discussion is concluded with a drawing activity introduced in the last page of the book. Students are asked to make a concept sketch of something they would design and develop if they were an engineer. They can use color and text to provide detail but the important part of this project is to use their own creativity to inspire their design. 'Engineering paper' is provided which is a type of graph paper that inspires an undoubtedly unique medium for their artwork.

The drawing of a concept sketch is one of the first steps in the engineering design process: Imagine (see Fig. 1 from www.EiE.org). In the development of something new, engineers produce a concept sketch or an illustration of how something (i.e., a new technology) may look or behave. Most often that "something" does not exist yet. For example, artists developed concept sketches for NASA and the space program, attempting to convey to the public what the Apollo probes would look like once they were developed. Although the space vehicles did not exist, the artwork provided a visual representation of the future. Students are reminded that by doing this activity, they are working as engineers and they are asked questions that prompt them to think and talk about their ideas. The purpose of this discussion is also to identify the science understandings they would need to have to design their idea. After several implementations of this activity with very diverse groups of students, we have found that science connections are maximized when students are asked what materials they would use for their design and why. A focus on design materials directs their thinking about the properties of materials and the purposeful selection of materials in engineering design. To enhance student talk, students can be paired in groups of two with their sketch. They are asked to share with each other their ideas, the materials they would use in their design, and how their designs would fill a need or purpose to help or improve our way of life. The partner student is then prompted to ask a question about the design to further engage in discussion. 
Figure 1. Engineering is Elementary (EiE) depicted the Engineering Design Process (EDP) appropriate for K-5 ${ }^{\text {th }}$ grade engineering education (retrieved from www.eie.org).

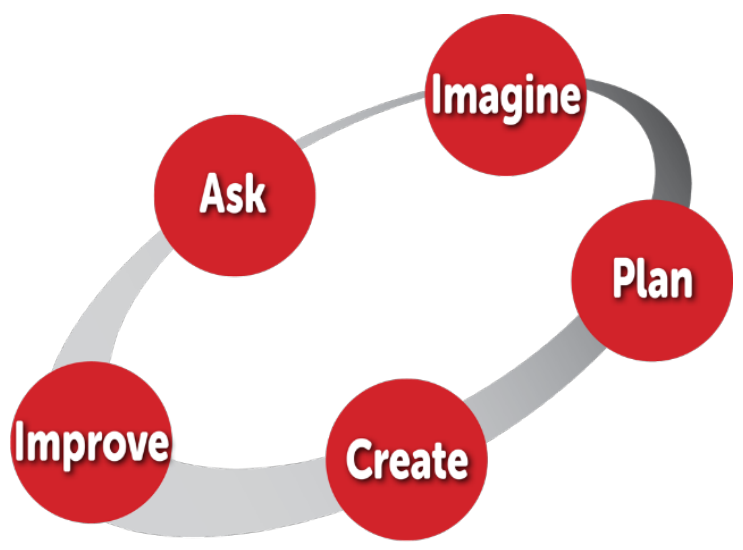

\section{Results: What We Learned}

The key learning objective in this lesson is teaching children that engineers design technologies. Our first goal was to keep the interest of students in the read aloud. During the read aloud we observed $98 \%$ were actively engaged by responding to the questions posed in the book, $0 \%$ lost interest at some point during the read aloud, and $2 \%$ were never engaged. To further illustrate the impact of this read aloud on students' emergent understanding of engineering, we collected concept sketches from students who did and did not receive the read aloud mini-lesson. We noticed two important trends. First, students who experienced the read aloud and discussion appeared to have developed an engineering identity. That is, about $90 \%$ of students did not hesitate to immediately picture themselves in this role either by engaging in the engineering design activity and 30\% graphically depicted themselves in the sketch (see Figure 2A). Equally important, these students also showed elevated knowledge in their drawings with direct correlations to topics covered in the book. For example, one student sketched a race car that turns into a rocket (Figure 2B); a three year old drew a fire truck and enthusiastically discussed the drag of a fire truck compared to a race car (Figure 2C).

Figure 2A.

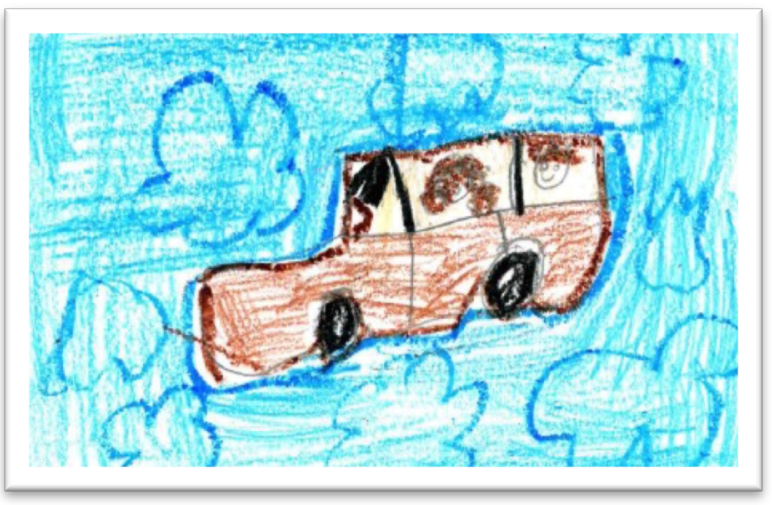


Figure 2B.

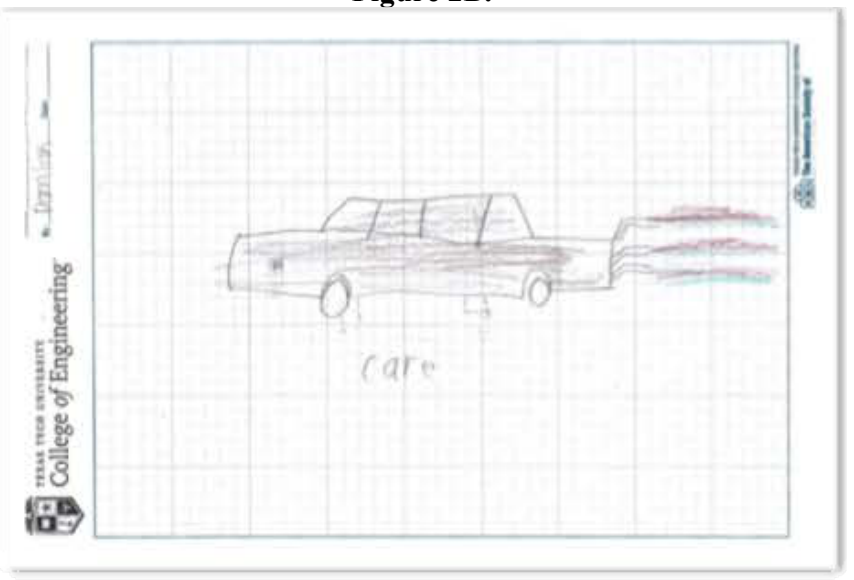

Figure 2C.

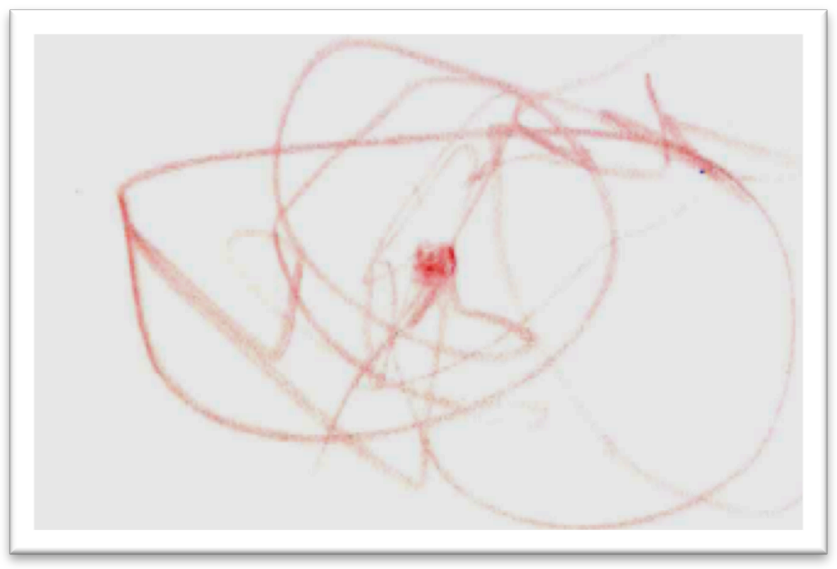

Figure 2. Concept sketches from a range of age levels. A. $2^{\text {nd }}$ Grade (7 year old) child drawing, text (not included in sketch) written by teacher reads "If I were an engineer, I would create..." text written by student artist reads "a flying car." Text written by teacher reads "This would be a great invention because..." text written by student artist reads "there will be less traffic." B. $3^{\text {rd }}$ Grade (8 year old) child, text not included in sketch reads: "Engineers make cars and rockets." C. Pre-school (3 years old) child drawing, text (not included in sketch) reads "I would make... a fire truck".

In contrast, students who had never been exposed to the mini-lesson or any type of engineering lessons (according to their teachers) overwhelmingly held the common belief, presented in the introduction, that engineers drive trains or work on trains as in Figure $3 \mathrm{~A}$ and B. Another prevalent trend in this group was the glaring lack of understanding of the work of engineers as illustrated in the flower image in Figure 3C. These students appear to be unable to make any connection to an accurate portrayal of engineering.

The contrast in both the expression of an engineering identity and an expanded understanding of the work of engineers including the design sketches illustrated in these examples are encouraging given the short duration of the read aloud and concept sketch activity. 
Figure 3A.

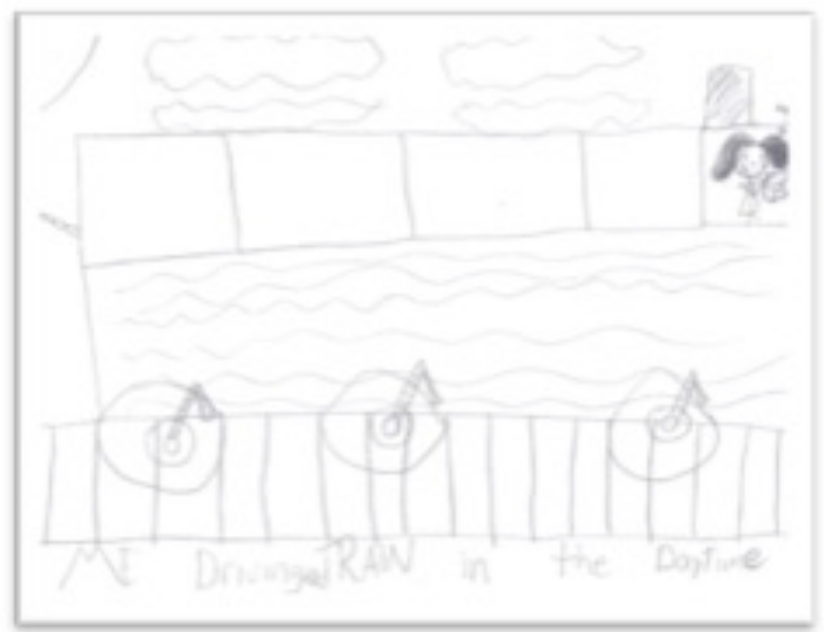

Figure 3B.

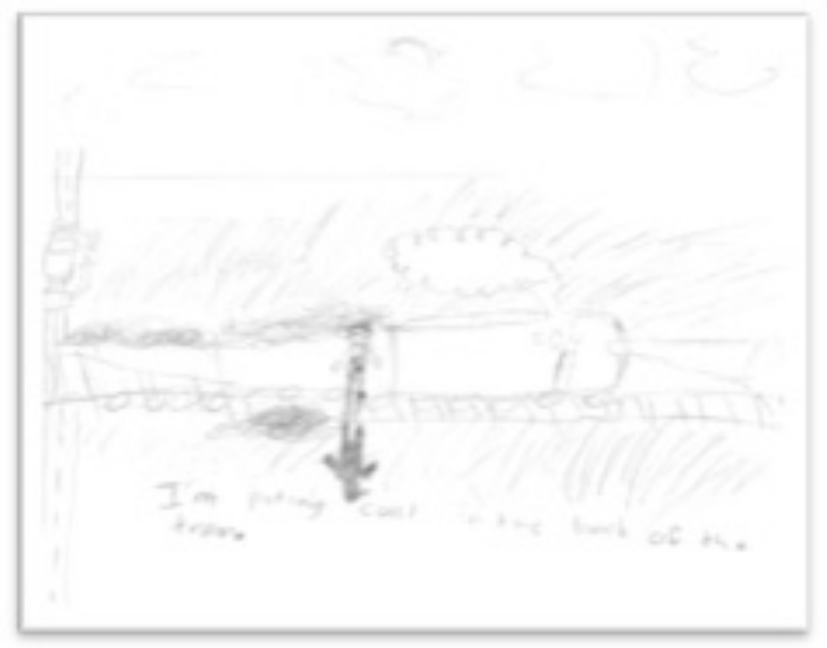


Figure 3C.

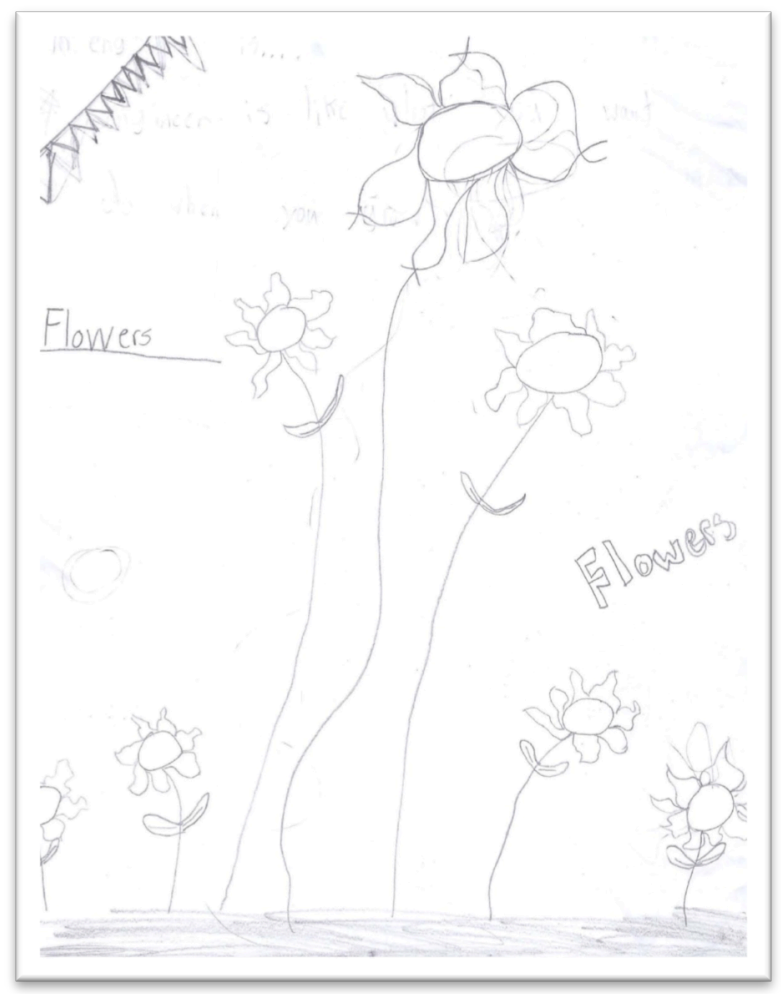

Figure 3. Concept sketches from children who had not read the book or participated in discussions about engineering. A. $1^{\text {st }}$ Grade child (6 years old), text reads "Me Driving a Train in the Daytime". $1^{\text {st }}$ grade child (7 years old) text reads "I'm putting coal in the back of the train". $1^{\text {st }}$ grade child (6 years old) text reads "Flowers-An engineer is like someone who grows something."

\section{CONCLUSIONS}

The purpose behind the development and use of instructional activities that incorporate engineeringcentered books, such as Engineering Elephants, is not mastery of all engineering concepts, but to introduce children to the idea that engineers design technologies and use science and math to do so. The second purpose is to foster creativity by imagining things that they could potentially create. Results show that engineering-centered literature not only inspires heightened levels of creativity and instilled a concrete sense for what engineers can do, it also appears to have initiated the development of an engineering identity that could shape a students' propensity to continue to seek engineering-based activities. This would be difficult for teachers given the paucity of engineeringcentered literature currently available to this age group. Therefore, this study supports the need for the development of additional engineering-centered literature that complements scientific curriculum such that the stories can more easily be integrated into every classroom and foster early enthusiasm for engineering.

Acknowledgements: We gratefully acknowledge support by a grant from the National Science Foundation under award number DRL-12487, and encouragement from our program manager, Dr. Edith Gummer. Texas Tech University IRB number for this project is 504973.

\section{REFERENCES}

Berry, R. Q., Thunder, K., \& McClain, O. L. (2011) Counter Narratives: Examining the Mathematics and Racial Identities of Black Boys who are Successful with School Mathematics. Journal of African-American Males in Education, 2(1), 1023. 
Bintz, W., Wright, P., Sheffer, J. (2010) Using copy change with trade books to teach earth science The Reading Teacher 64 (2), 106-119.

Clements, D. H., Sarama, J., Spitler, M. E., Lange, A. A., \& Wolfe, C. B. (2011). Mathematics learned by young children in an intervention based on learning trajectories: A large-scale cluster randomized trial. Journal for Research in Mathematics Education, 42(2), 127-166.

Clements, D. H., Sarama, J., Wolfe, C. B., \& Spitler, M. E. (2013). Longitudinal evaluation of a scale-up model for teaching mathematics with trajectories and technologies: Persistence of effects in the third year. American Educational Research Journal, 50(4), 812 -850. doi: 10.3102/0002831212469270 Cunningham, C.M. \& Lachapelle, C.P. (in press). Designing engineering experiences to engage all students. In J. Strobel, S. Purzer, M. Cardella (Eds.), Engineering in PreCollege Settings: Research in Practice. Rotterdam: Sense Publishers.

Donohoo, J. (2010) Learning how to learn: Cornell notes as an example Journal of Adolescent \& Adult Literacy 54 (3), $224-227$.

Duncan, G.J., Dowsett, C.J., Claessens, A., Magnuson, K., Huston, A.C., Klebanov, P., Pagani, L.S., Feinstein, L., Engel, M., Brooks-Gunn, J., Sexton, H., Duckworth, K., Japel, C. (2007). School readiness and later achievement. Developmental Psychology, 43,1428-1446.

Fang, Z., Wei, Y. (2010) Improving middle school student's science literacy through reading infusion Journal of Educational Research 103 (4), 262-273.

Geary, D. C. (2013). Early foundations in mathematics learning and their relations to learning disabilities. Current Directions in Psychological Sciences, 22(1). 23-27.

Gibbons, P. (2003). Mediating language learning; Teacher interactions with ESL students in a content-based classroom. TESOL Quarterly, 37(2), 247-273.

Hunt, E.M. and Pantoya, M.L. 2010. Engineering Elephants. AuthorHouse Publishing, ISBN: 978-1-4490-5816-6.

Kang, H., \& Lundeberg, M. A. (2010). Participation in science practices while working in a multimedia case-based environment. Journal of Research in Science Teaching, 47(9), 1116-1136.

Mantzicopoulos, P., Samarapungavan, A., \& Patrick, H. (2009). "We learn how to predict and be a scientist: Early science experiences and kindergarten children's social meanings about science, Cognition and Instruction 27, 312-369.

Mantzicopoulos, P., Patrick, H., \& Samarapungavan, A. (2008). Young children's motivational beliefs about learning science, Early Childhood Research Quarterly 23, 378-394.

National Academies Press, Successful K-12 STEM Education: Identifying Effective Approaches in Science, Technology, Engineering, and Mathematics (2011).

National Academies Press, STEM Integration in K-12 Education: Status, Prospects, and an Agenda for Research (2014).

National Research Council (NRC, 2007) Taking Science to School: Learning and Teaching Science in Grades K-8. Washington, DC: National Academy Press. http://www.nap.edu/catalog.php?record id=11625

National Research Council (2008). Early Childhood Assessment: Why, What, and How? Committee on Developmental Outcomes and Assessments for Young Children, Catherine E. Snow and Susan B. Van Hemel, (Eds.). Board on Children, Youth and Families, Board on Testing and Assessment, Division of Behavioral and Social Sciences and Education. Washington, DC: The National Academies Press.

National Research Council. (2012). A Framework for K-12 Science Education: Practices, Crosscutting Concepts, and Core Ideas. Committee on a Conceptual Framework for New K-12 Science Education Standards. Board on Science Education, Division of Behavioral and Social Sciences and Education. Washington, DC: The National Academies Press.

Osborne, J. W., \& Jones, B. D. (2011). Identification with academics and motivation to achieve in school: How the structure of the self influences academic outcomes. Educational Psychology Review, 23, 131-158.

Romance, N.R. and Vitale, M.R. (1992). A curriculum strategy that expands time for in-depth elementary science instruction by using science based reading strategies: effects of a year-long study in grade four. Journal of Research in Science Teaching 29(6), 545-554.

STEM Smart Brief, STEM Smart: Lessons Learned From Successful Schools, Nurturing STEM Skills in Young Learners, PreK3; National Science Foundation Publication, Prepared by the Community for Advancing Discovery Research in Education (CADRE) at the Education Development Center, Inc. (2011) Retrieved from http://successfulstemeducation.org/sites/successfulstemeducation.org/files/Specialized\%20STEM\%20Secondary\%20Sc hools FINAL 0.pdf

Was, C. A., Al-Harthy, I., Stack-Oden, M., \& Isaacson, R. M. (2009) Counter Narratives: Examining the Mathematics and Racial Identities of Black Boys who are Successful with School Mathematics, Electronic Journal of Research in Educational Psychology, 7(2), 627-62. 